\title{
Shoot formation model (architectural model) Phlomoides oreophila
}

\author{
Elizaveta K. Komarevtseva ${ }^{1 *}$, and Alexandra A. Guseva ${ }^{1}$ \\ ${ }^{1}$ Central Siberian Botanical Garden SB RAS, 630090 Novosibirsk, Russia
}

\begin{abstract}
The morphological characteristics of Phlomoides oreophila, which grows in the Altai Mountains and Southeast Kazakhstan, are given. It is established that the species belongs to the monopodial-rosette model of shoot formation. The main structural unit is a perennial basal (skeletal) rosette shoot. Its annual growths form an epigeogenic oblique-orthotropic rhizome. An elementary shoot appears during 1 growth period and carries the vegetative and generative parts. The formula of the functional zones of the elementary shoot is determined: the inhibition zone $\rightarrow$ [innovation zone $] \rightarrow$ amplification zone $\rightarrow$ apical bud. It was established that the boundaries of the elementary and annual shoots do not coincide. Elementary shoot includes spring leaf generation (inhibition zone), summer leaf generation with axillary vegetative buds (innovation zone) and vegetative-generative buds (amplification zone). Vegetative-generative shoots appear only after wintering the following spring. They are located below the rosette leaves of the spring generation (this is the beginning of a new elementary shoot). As a result, the annual shoot includes the elementary shoot of the current year, as well as the amplification zone of the elementary shoot of last year.
\end{abstract}

The structure of a perennial herb polycarpic plant is determined by the growth mode of its shoot systems. A monocarpic shoot is the main structural unit of an individual with sympodial growth, while with monopodial growth, the structural unit is an elementary shoot, including the vegetative and generative parts. Elementary shoot appears during 1 growth period. The set of elementary shoots is a perennial vegetative-generative monopodial shoot [1]. The monopodial growth model is quite common and occurs in different families: Rosaceae, [1, 2]; Violaceae [3]; Fabaceae [4], Lamiaceae [5]. One type of functional-zonal structure of the elementary shoot was determined for the studied monopodial species. It consists of the following zones: inhibition zone (has only resting buds) $\rightarrow$ innovation zone (shoots of the next order develop from lateral winter buds) $\rightarrow$ amplification zone (generative shoots form from lateral buds) $\rightarrow$ apical bud [6]. The features of this shoot formation model are not well understood. Therefore, Phlomoides oreophila (Kar. \&Kir.) Adylov, Kamelin\&Makhm. was chosen as the object of work, as a poorly studied mountain species with monopodial shoot growth. The aim of the work is to give a morphological characteristic of $P$. oreophila and to reveal the functional-zonal structure of its monopodial rosette shoot.

\footnotetext{
* Corresponding author: elizavetakomarevceva@yandex.ru
} 
P. oreophila (fam. Lamiaceae) is a Eurasian mountain species, the area of which passes through mountain systems: from Mountain Altai, through the mountains of Southeastern Kazakhstan (Tarbagatai, Dzhungarsky Alatau), Western and Central Tien-Shan to the Pamir-Alai (Gissara-Alai). P. oreophila grows in forest-steppe, forest belts, up to subalpine. Its characteristic habitats are rocky slopes; it prefers carbonate rocks [7-9]. The research took place in Mountain Altai (population 1) and in Kazakhstan (population 2). Population 1 is located on the southeastern stony slope in the bushy oat-feather grass steppe, population 2 - on the alpine meadow on the Saur ridge. Shoot morphogenesis is described by T.I. Serebryakova [10]. Functional zoning of the shoot system was carried out according to I.V. Borisova, T.A. Popova [6], the type of inflorescence was determined by T.V. Kuznetsova and A. K. Timonin [11].

P. oreophila is a perennial polycarpic monopodial rosette short-rhizome plant (Fig. 1). The main structural unit of the generative individual is a perennial monopodial basal rosette shoot (skeletal axis). Its annual growths are drawn into the soil due to the contractile activity of the adventitious roots. An epigeogenic oblique-orthotropic rhizome is formed up to $20 \mathrm{~cm}$ long and $1-2 \mathrm{~cm}$ in diameter, growing from the apical part and dying from the distal one. The main root dies in the immature state. Adventitious roots up to $10 \mathrm{~cm}$ long, branching up to the $3 \mathrm{rd}$ order. The buds of the last two annual growths are kept alive on the rhizome. The main skeletal axis may branch. A bush is formed, consisting of 2-3 skeletal monopodial axes (rosette shoots). But more often the uniaxial structure of an adult remains. So, $P$. oreophila belongs to the monopodial rosette shoot formation model described by $\mathrm{T}$. I. Serebryakova [12].

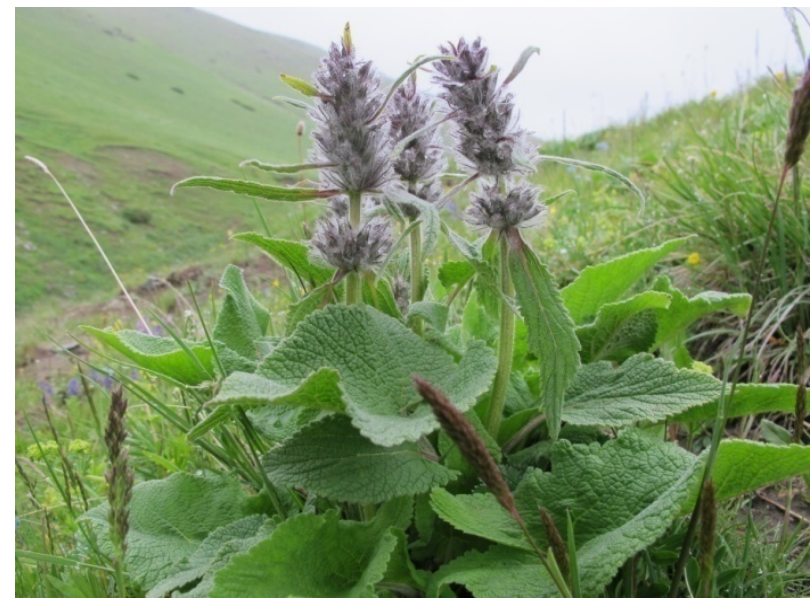

Fig. 1. Generative individual P. oreophila (author V.A. Cheryomushkina)

The species blooms in late May and early June. Until mid-June, 1-2 (up to 4) generative shoots develop in the axils of last year's dead leaves. Generative shoots (length 13-38 cm) consist of 2 metamers with foliage leaves and 3-5 metamers with bract leaves. Inflorescences (2-3-membered dichasia) are formed in their axils, and their complex forms an open spike-like thyrsus. The polynomial dichasia consists of 6-14 flowers. Large rosette leaves (1st generation) grow simultaneously with the growth of generative shoots. These leaves (2-4 pairs) represent the beginning of a new elementary shoot. The axillary buds of these leaves never participate in the shoot formation.

At the beginning of June, the apical bud of a skeletal shoot consists of 7-8 rudimentary metamers, on which 3-4 pairs of embryonic leaf (the 2nd generation of this year), 3 pairs of rudimentary rosette spring leaves of the next year and a vegetative shoot apex with leaf 
primordia. All leaf rudiments have axillary buds of varying degrees of development. The buds in the axils of the next year's leaf rudiments are small. Large vegetative and (or) vegetative-generative buds with a capacity of 1-4 metameres develop in the axils of the 2 nd generation leaf rudiments of this year. The vegetative and vegetative-generative buds proportion depends on the age of the plant. Young generative plants have 1-2 vegetativegenerative buds on only one middle metamer. These buds prevail over the vegetative ones or completely replace them in mature generative individuals. The capacity of vegetativegenerative buds is 4 metamers at the beginning of June: 2 metamers only with leafy rudiments and 2 metamers with leafy and axillary generative rudiments. There are frequent interruptions in flowering caused by weather conditions of a particular year, which affect the development of vegetative-generative shoots from already formed buds after overwintering. Under adverse conditions, part of these buds (or all) do not germinate and remain on the skeletal shoot, gradually dying.

Leaves of the 2nd (summer) generation grow back in July. They are less developed in comparison with spring rosette leaves. Their axillary buds are fully formed until the end of the vegetation season. The capacity of vegetative buds is 4 metameres. Capacity of the vegetative-generative buds increases to 6-7 metameres, of which the 4-5 upper metameres with generative rudiments. In the fall, both generations of leaves die off.

As a result of the morphological analysis, the following was established. Generative shoots, the beginnings of which were laid in the previous vegetation season, grow only after wintering in spring and are located below spring rosette leaves, which represent the beginning of a new elementary shoot (Fig. 2). This is due to the fact that the formation of an elementary shoot does not fit in one vegetation season. The final development of its structures (axillary generative shoots) occurs in the spring of next year. A similar "lag" in the development of the generative sphere of the plant was found in other monopodially growing species of the genus Gentiana L. [13], Potentilla L. [2], and Dracocephalum imberbe Bunge (Lamiaceae) [5].

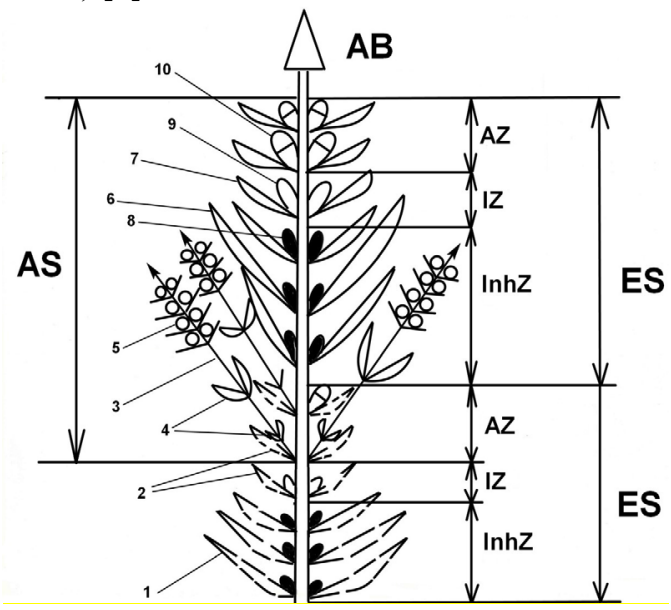

Fig. 2. The structure of the skeletal monopodial rosette shoot of Phlomoides oreophila. Note: 1 dead leaf of the 1-st generation; 2 - dead leaf of the 2-nd generation; 3 - vegetative-generative shoot; 4 - the middle leaf of the vegetative-generative shoot; 5 - polynomial dichasia; 6 -green leaf of the 1st generation; 7 - green leaf of the 2-nd generation; 8 - vegetative bud in the zone of inhibition; 9 vegetative bud in the innovation zone; 10 - vegetative-generative bud. ES - elementary shoot; AS annual shoot; $\mathrm{AB}$ - apical bud; InhZ - inhibition zone; IZ - innovation zone; AZ - amplification zone.

The following functional zones can be distinguished in the structure of the elementary shoot of $P$. oreophila. Part of the shoot with spring rosette leaves that have axillary sleeping 
buds corresponds to the inhibition zone. There is a innovation zone (lower 1-2 metamer with vegetative axillary buds) and an amplification zone (upper 3-4 metamer with vegetative-generative buds) in the area with summer rosette leaves. The innovation zone is often inactive because lateral rosette shoots rarely sprout buds of this zone. The size of the amplification zone depends on the ontogenetic state of the individual. At the beginning and end of the generative period, it occupies 1-2 upper metameres with leaves of summer generation. Vegetative-generative buds develop in the axil of all leaves of the 2nd generation of mature generative individuals. The zones of elementary shoot of $P$. oreophila have the following sequence [not always expressed zones are indicated in brackets]: inhibition zone $\rightarrow$ [innovation zone] $\rightarrow$ amplification zone $\rightarrow$ apical bud. The same sequence was described by I.V. Borisova and T.A. Popova [6] for Coronaria coriacea, Lindelophia macrostyla, Rosularia paniculata, species of the same shoot formation model. But the innovation zone of $P$. oreophila is not always expressed and can be completely replaced by the amplification zone. An elementary shoot ends with an apical bud, in which in autumn there are rudiments of rosette leaves of the 1st and 2nd generation generations.

Thus, Phlomoides oreophila is a variant of the monopodial rosette model of shoot formation. The main structural unit is a perennial skeletal rosette shoot, the annual growth of which forms an epigeogenic oblique-orthotropic rhizome. The boundaries of the annual and elementary shoots do not coincide. Elementary shoot formula: inhibition zone $\rightarrow$ [innovation zone] $\rightarrow$ amplification zone $\rightarrow$ apical bud. The annual shoot includes the amplification zone of the elementary shoot of last year and the elemental shoot of the current year.

We would like to thank Dr. Vera Cheremushkina for her helpful advice and the photo provided.The work was carried out with the financial support of the grant of RFBR within the framework of scientific project № 18-04-00621-a and project of the State Assignment of Central Siberian Botanical Garden of the Siberian Branch of the Russian Academy of Sciences № AAAA-A17-117012610053-9.

\section{References}

1. T. I. Serebryakova, L. V. Petukhova, Bull.MOIP. Otdel. Biol. 83, 51-64 (1978).

2. T. I. Serebryakova, N. R. Pavlova, Bot. J. 71, 154-167 (1986).

3. T. I. Serebryakova, T. V. Bogomolova, Bot. J. 69, 729-741 (1984).

4. T. D. Mikhaylova, Biol. nauki. 6, 7-14 (1972).

5. G. R. Denisova, V. A. Cheremushkina, Sib. Bot. Vest. 2, 61-66 (2007).

6. I. V. Borisova, T. A. Popova, Bot. J. 75, 1420-1426 (1990).

7. A. Orazova, Flora Kazakhstana (Alma-Ata, 1964).

8. T. A. Adylov, A. M. Makhmedov, Labiateae - Phlomoides. Opredelitel' rasteniy Sredney Azii (Tashkent, 1987). In Russian

9. V. M. Doron'kin, Flora Sibiri (Novosibirsk, 1997).

10. T. I. Serebryakova, Morfogenez pobegov i evolyutsiya zhiznennykh form zlakov (Moscow, 1971). In Russian

11. T. V. Kuznetsova, A. K. Timonin, Sotsvetiye: morfologiya, evolyutsiya, taksonomicheskoye znacheniye (primeneniye komplementarnykh podkhodov) (Moscow, 2017). In Russian

12. T. I. Serebryakova, Bull.MOIP. Otdel. Biol. 82, 112-128 (1977).

13. T. I. Serebryakova, Bull.MOIP. Otdel. Biol. 84, 97-109 (1979). 